Fecha de recepción: abril 2021

Fecha de aprobación: mayo 2021

Fecha publicación: junio 2021

\section{Cruces entre arte contemporáneo y artesanía: la utilización del repujado de estaño y la fabricación de exvotos en el campo de la pintura expandida}

Belén Mazuecos Sánchez ${ }^{(1)}$

\begin{abstract}
Resumen: Las transferencias culturales entre arte contemporáneo y artesanía han provocado la proliferación de proyectos artísticos que recurren al sincretismo de técnicas y materiales. Este artículo analiza la producción artística de la autora basada en la técnica del repujado de estaño e inspirada en la fabricación de exvotos, fenómeno extendido en países católicos o protestantes, siendo Andalucía una de las regiones de España con más incidencia.

Se presentan varias obras en las que se reinterpreta esta tradición, generando un nuevo universo simbólico con exvotos artesanales.
\end{abstract}

Palabras clave: arte contemporáneo - artesanía - repujado de estaño - exvotos - pintura expandida - hibridación.

[Resúmenes en inglés y portugués en las páginas 97-98]

(1) Belén Mazuecos, es Profesora Titular del Dpto. de Pintura, es Doctora con mención europea (Universidad de Granada). Licenciada en BB.AA. (UGR y Accademia di Belle Arti di Brera, Milán, Italia, 2001) y Antropología Social y Cultural (UGR, 2011). 3º Premio Nacional Fin de Carrera a los Estudios en Bellas Artes (Ministerio de Educación, Cultura y Deporte, Gobierno de España). Obtuvo las Becas FPDI (Formación de Personal Docente e Investigador, Junta Andalucía,) y FPU (Formación de Profesorado Universitario, MECD). Ha sido Vicedecana de Cultura y Directora del Área de Artes Visuales de la UGR . Ha dirigido y participado en proyectos de $\mathrm{I}+\mathrm{D}+\mathrm{i}$ internacionales. Ha obtenido diversos premios y reconocimientos por su actividad artística e investigadora.

\title{
Introducción
}

Las transferencias culturales entre arte contemporáneo y artesanía han provocado la proliferación en la escena artística actual de proyectos artísticos que recurren a la hibridación entre disciplinas y al sincretismo de técnicas y materiales. 
En este artículo se analizará una de las líneas de investigación y producción artística personal de la autora en relación a la técnica del repujado de estaño, inspirándose en la práctica popular de fabricar exvotos, una tradición de alto valor etnográfico renovada hoy a consecuencia de la pandemia y cuyo uso se ha extendido en países predominantemente católicos o protestantes, siendo Andalucía una de las regiones en España con más incidencia del fenómeno exvotista (Reder Gadow, 2013), donde las ofrendas populares siguen tapizando literalmente los muros de muchas de nuestras iglesias y santuarios.

El alto impacto de esta tradición en determinados contextos del sur de nuestro país ha sido objeto de reflexión, por ejemplo, por parte de la artista andaluza Pilar Albarracín (Sevilla, España, 1968), cuya obra remite a muchos elementos del folclore popular. En su instalación "Techo de ofrendas" (2004), recrea la costumbre de colgar exvotos en lugares de culto mediante vestidos de flamenca suspendidos del techo, mientras que en "T.C.A (mantón)" (1997), borda con hilo de seda un corazón sobre un mantón de manila, conectando también con la idea de exvoto.

En esa misma línea, Marina Vargas (Granada, España, 1980) recurre a la estética exvotista mexicana, produciendo series como "Me sobra el corazón" (2013), representando diferentes versiones del sagrado corazón de Jesús con técnica mixta sobre tapiz bereber.

Del mismo modo el proyecto "Letanías" del granadino Andrés Monteagudo (Granada, España, 1970), se aproxima a esta singular tradición, inspirándose en los exvotos religiosos, mediante el autorretrato fotográfico, recubriendo su cuerpo desnudo con estos objetos de metal representando diferentes elementos de nuestra anatomía para hablar de la identidad fragmentada.

En las siguientes páginas se analizarán en profundidad varias obras de la autora como estudios de caso, inspiradas en los exvotos artesanales realizados con láminas de metal que reproducen el cuerpo entero de una persona o partes disgregadas (extremidades, órganos, etc.,) pero, en este caso, introduciendo nuevos e inusuales elementos. En los proyectos "Bombyx-mori: memento mori", "La habitación de la entomóloga" "Altarpiece", "Ojos que no ven" o "Allí donde nace el peligro crece la salvación" la narrativa se sustenta en el carácter simbólico de los elementos repujados en estaño, que la autora dispone en una suerte de relicarios o incluye en instalaciones.

\section{La tradición del exvoto: religiosidad + arte popular. Algunos antecedentes en el ámbito de la pintura}

La práctica de fabricar exvotos, intercesores íntimos con Dios, la Virgen o los santos, vehículos eficaces para expresar gratitud por haber sido salvado de una enfermedad o desastre gracias a lo que todos perciben como intervención divina, arranca de los "anathemata" de la Antigüedad griega y romana. Elaborar una imagen como señal de agradecimiento a Dios se creía el modo más directo y eficaz de hacerlo. Liberaba a la persona de la deuda contraída y la eximía de futuras demostraciones de agradecimiento, pues el objeto seguiría siendo un recordatorio perpetuo de gratitud por el bien recibido, mientras que las ora- 
ciones siempre eran transitorias, había que renovarlas y solo si uno era pudiente tenía la seguridad de que las plegarias se replicarían después de su muerte.

Los objetos votivos no tienen que ser necesariamente pinturas o esculturas (dentro de esta categoría se distinguen desde pinturas de los grandes maestros, hasta los cuadros más humildes pintados sobre latón o cristal); pequeñas figuritas de metal, cera, papel maché, etc., con forma de brazos, piernas, dedos, torsos, ojos, orejas, narices y bocas o incluso fotografías o los mismos objetos que intervinieron en el hecho salvífico (como prendas de vestir o utensilios domésticos y agrícolas) hacen de mediadores para expresar agradecimiento por la conservación de la parte del cuerpo sanada o implicada en el accidente.

Ris-Rettenbeck (1972, p. 164) distingue algunos elementos iconográficos constantes en estas imágenes sagradas: $1^{\circ}$ ) la representación del operario celestial, sea imagen milagrosa, ser divino, santo o lugar sagrado; $2^{\circ}$ ) el retrato de la figura que vuelve los ojos al dominio celeste y de quienes lo ponen en contacto con él o rezan por el suplicante; $3^{\circ}$ ) el suceso o circunstancia que fue la causa de la comunicación inicial entre el personaje terreno y la persona o símbolo divino; y $4^{\circ}$ ) la inscripción que deja constancia de la circunstancia, el suceso o la esperanza.

Antes de presentar nuestro proyecto artístico personal, revisaremos tres ejemplos de obras de artistas de diferentes épocas (S. XIX, S. XX y S. XXI) influenciados por la tradición del exvoto desde la práctica de la pintura y el dibujo: el retrato pictórico del Doctor Arrieta de Goya, la obra "Accidente" de Frida Kahlo y los dibujos curativos de Aitor Saraiba, en el contexto del arte actual.

Goya (Fuendetodos, Zaragoza, España, 1746-Burdeos, Francia, 1828), pintó en 1820 en la Quinta del Sordo, su cuadro dedicado al Doctor Arrieta, en agradecimiento a los cuidados proferidos por el médico que trató y curó al pintor de una grave enfermedad padecida un año antes (posiblemente tifus). En la escena, Goya se autorretrata agonizante, siendo asistido por el doctor que le da a beber una medicina.

En la parte inferior de la obra reza la siguiente inscripción en una cartela: "Goya agradecido, a su amigo Arrieta: por el acierto y esmero con que le salvó la vida en su aguda y peligrosa enfermedad, padecida a fines del año 1819, a los setenta y tres años de su edad. Lo pintó en 1820 ".

Más de un siglo después, en 1926, Frida Kahlo (Coyoacán, Ciudad de México, México, 1907-ibid., 1954) evocará en el dibujo a lápiz titulado "Accidente", un suceso traumático acontecido también el año anterior. La artista mexicana utilizó la plancha metálica en muchas de sus obras, observando las peculiaridades de la imaginería votiva, pero en esta ocasión nos centraremos en la pieza que representa el accidente que cambiará su existencia. En 1925, volviendo de la escuela el autobús en que viajaba la joven Frida se interpuso en la trayectoria del tranvía de Xochimilco al intentar cruzar los raíles sobre los que aquél se aproximaba. Este episodio, punto de inflexión en su vida, será el inicio para la pintora mexicana de un lento suplicio regenerado hasta la muerte. Atravesada por el pasamanos del vehículo y con un diagnóstico que recogía múltiples lesiones de extrema gravedad [fractura de la tercera y cuarta vértebras lumbares, tres fracturas de la pelvis, once fracturas en el pie derecho, luxación del codo izquierdo, herida profunda en el abdomen producida por una barra de hierro que entró por la cadera izquierda y salió por el sexo, desgarrando el labio izquierdo-, peritonitis aguda, cistitis que requiere una sonda durante 
muchos días (Kettenmann, 1994)], en el hospital de la Cruz Roja los médicos la intervinieron sin esperanzas pero, milagrosamente, sobrevivió a la operación a pesar de su estado crítico. Posteriormente, Frida representará el accidente en un dibujo a lápiz que, como la popular pintura de exvoto no observa las reglas de la perspectiva sino la jerarquía de escala. En éste refleja la colisión y en el registro inferior su cuerpo inmóvil (mucho más grande que el resto de las personas representadas) en una camilla de la Cruz Roja. Su rostro se desdobla y contempla la escena con preocupación. En la parte izquierda dibuja la fachada de "la casa azul", destino de la pintora, y en el ángulo superior del mismo lado un sol que se precipita sobre la línea de horizonte (Jamis, 2000), Quedan de esta forma perfectamente delimitadas las coordenadas espacio-temporales del fatídico evento. Más de tres lustros después, en 1943, Kahlo retomará por segunda y última vez esta dolorosa experiencia reinterpretando un cuadro votivo que planteaba un accidente similar al suyo. Bastaron pocas modificaciones para personalizarlo; añadió el entrecejo a la víctima y la siguiente leyenda de agradecimiento: "Los esposos Guillermo Kahlo y Matilde C. De Kahlo dan las gracias a la Virgen de los Dolores por haber salvado a su niña Frida del accidente acaecido en 1925 en la esquina de Cuahutemozin y Calzada de Tlalpan".

Por último, en la segunda década del nuevo milenio, citaremos el proyecto "Dibujos curativos” (2017) del artista Aitor Saraiba (Talavera de la Reina, Toledo, 1983). Como explica Fernando Pérez:

Se trata de tener entre tus manos una obra de arte única, hecha solo para ti o para aquel que necesita algo más que un medicamento genérico. El valor añadido de la inmediatez, lo cercano de lo propio y lo privado, la sugerencia de lo íntimo y la comunicación entre el emisor y el receptor de la obra-medicina se vive y se experimenta de una forma única en esta acción.

Podríamos decir que estamos hablando de la mixtura de la generosidad entre un chamán del arte y un espectador-actor sujeto a una terapia doble, la que experimenta aquel que es capaz de contarle al artista su necesidad y la necesidad del artista de compartir ese plus que solo los seres más especiales tienen, aquellos que sin ser genios todavía donan parte de ese espacio efímero a otro sin pedirle nada a cambio ${ }^{1}$.

El dibujo adquiere aquí una dimensión performativa y terapeútica que culmina con la realización de una pieza de carácter salvífico que representa los deseos de la persona que necesita sanar, garantizando su cumplimiento.

\section{Investigación y producción artística en el campo de la pintura expandida}

Llegados a este punto, abordaremos mi propia producción artística, por lo que recurriré a la primera persona para la redacción de esta sección del artículo. Mi trabajo se sitúa en el campo de la pintura expandida (Barbancho, 2009; Barro, 2015; Perniola, 2015; Vázquez, 2016), pivotando desde el dibujo y la pintura propiamente dichos, hacia los territorios de 

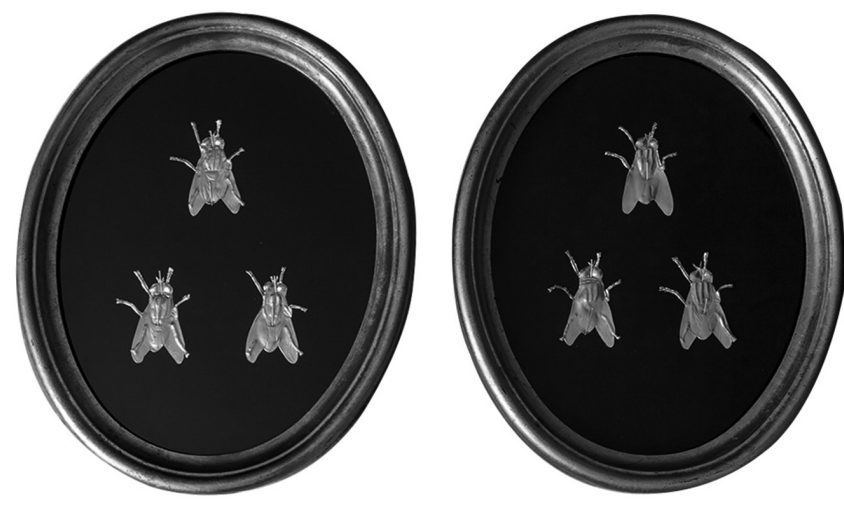

Figura 1. Belén Mazuecos,

"Naturaleza muerta con moscas", díptico $34 \times 27 \mathrm{~cm} \mathrm{c} / \mathrm{u}$, exvotos de estaño repujado sobre tela de brocado. Feria Marte, Castellón (España), 2014².

la fotografía, el arte de objetos, la instalación o la intervención site specific. Desde esta práctica híbrida y multidisciplinar, la autobiografía visual (Guash, 2009) vertebra toda mi producción (imbricando argumentos relacionados con mi historia personal -tribulaciones identitarias, reflexiones sobre la vida y la muerte, rol en la sociedad desde la perspectiva de género y en el propio ecosistema artístico, cuestionamiento del sentido de la práctica artística, etc.- con episodios de la convulsa Historia con mayúsculas que actualmente vivimos) (Figura 1).

Una experiencia banal o un pequeño estímulo (una imagen, un objeto, una palabra, un suceso, etc.,) desencadenan un proceso de investigación sofisticado que desemboca en la articulación de un concepto más complejo por asociación de ideas y en la búsqueda de la adecuación de los medios empleados al propósito expresivo concreto. Normalmente, estas experiencias o reflexiones motivan el comienzo de una obra o una serie y los proyectos van creciendo de forma rizomática (unas piezas llevan a otras y entre ellas comienzan a interconectarse hasta configurar series y proyectos de mayor envergadura).

\section{Proyectos artísticos personales con exvotos de estaño repujado e iconografía}

En los últimos años he trabajado -desde el ámbito de la instalación y la intervención site specific- en la revisión del tradicional género de la vanitas, repujando exvotos de metal para recrear una suerte de gabinetes de curiosidades o cámaras de las maravillas, que evocan temas clásicos transcendentales como la fugacidad del tiempo (tempus fugit) o la caducidad de la vida (carpe diem), con los que el público puede identificarse fácilmente Figura 2). 


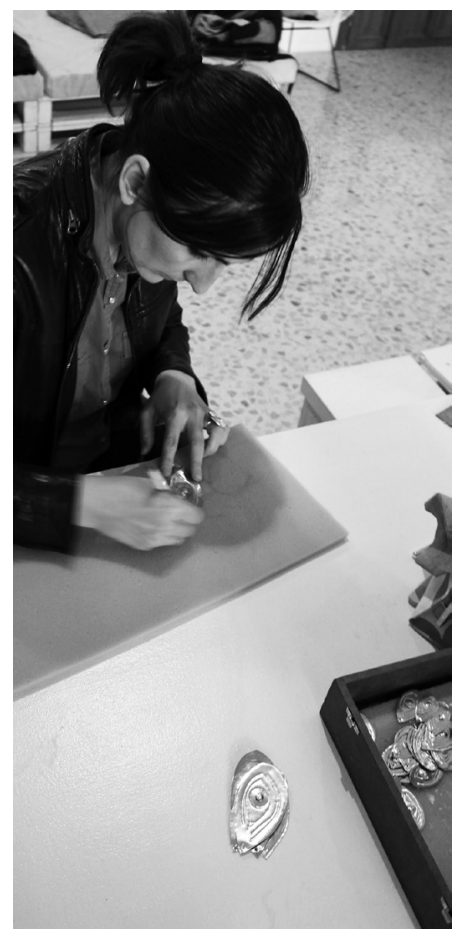

2

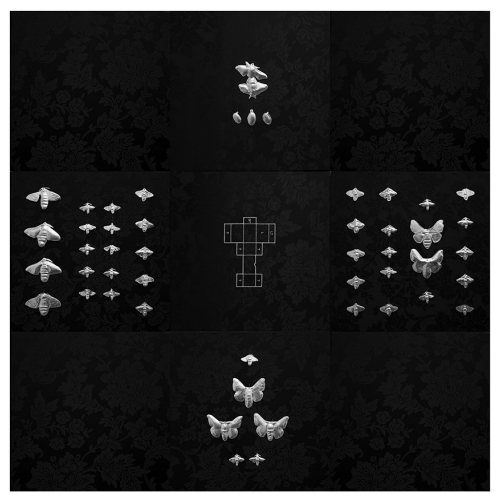

4

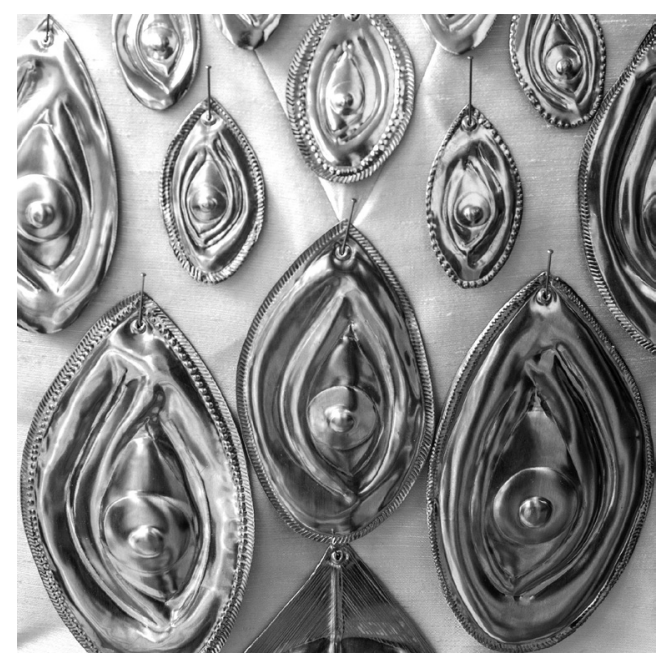

3

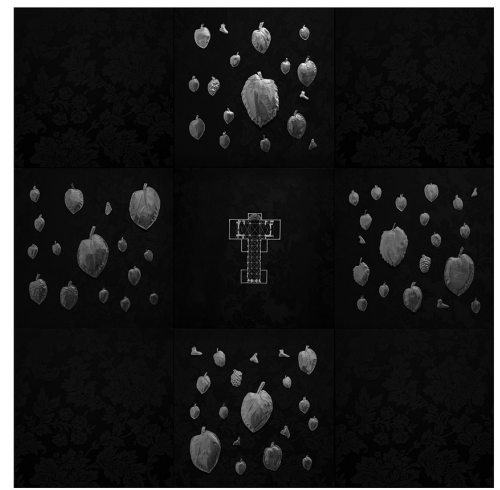

Figura 2. Belén Mazuecos repujando el estaño para producir algunos de sus exvotos. Figura 3. Exvotos producidos por la autora para su instalación "Ojos que no ven”, El Arsenal, Córdoba (España), Festival Miradas de Mujeres MAV, 2014. Figura 4. Belén Mazuecos, “Bombyx Mori-Memento Mori”. Exposición "Doce-Dodici", instalación, dimensiones variables, en exposición colectiva "Doce-dodici" en Instituto Cervantes de Milán (Italia), 20134. 
En algunas de mis piezas, el simbolismo de los materiales y la laboriosidad del trabajo artesanal (capaz de condensar en la propia obra el paso del tiempo) resulta determinante. Esta condición puede apreciarse no sólo en los trabajos con estaño repujado sino también en otras piezas producidas con jabón artesanal, cera, pan de oro, bordados con hilo de oro y plata, etc., que encierran sugerentes connotaciones vinculadas al ciclo vital. No obstante, en este artículo nos centraremos solo en las piezas realizadas con estaño repujado (Figuras 3 y 4$)$.

Estos proyectos tienen su origen en la obra "Bombyx Mori”, finalista en los Premios Pepe Espaliú a las Artes Visuales en 2007. Un díptico (30 x 30 x $6 \mathrm{~cm}$ cada módulo) en el que las alas desmembradas de la polilla del gusano de seda clavadas sobre tela de brocado roja iban metamorfoseándose en exvotos de pies, haciendo referencia al ciclo vital y estableciendo una analogía entre la transformación del gusano en mariposa y el proceso de envejecimiento y enfermedad que conduce inexorablemente a la muerte. Mientras que la pieza de la izquierda evocaba un relicario con exvotos, la de la derecha presentaba un dibujo a carboncillo de los capullos de seda construidos por los gusanos como protección, recubierto por una capa protectora de cera y parafina, con el texto "ser, seres, serikum"

\section{Proyecto "La habitación de la entomóloga"}

Uno de los proyectos que confirmó esta línea de trabajo e investigación fue "La habitación de la entomóloga”, una intervención site specific realizada en la Galería Isabel Hurley (Málaga, España) en el contexto de la exposición "Nadie hablará de nosotros cuando hayamos muerto", comisariada por el artista David Escalona (bajo el pseudónimo Martha Hallot), que revisaba el tradicional género de la vanitas, recreando un gabinete de curiosidades, una "wunderkammer", donde la metamorfosis del gusano de seda (bombyx mori) era utilizada como metáfora que evocaba temas clásicos transcendentales como la fugacidad del tiempo (tempus fugit) y la caducidad de la vida (carpe diem) (Figura 5).

El concepto clave que vertebra las diferentes piezas que integran la instalación "La habitación de la entomóloga" es la muerte. La obra recrea el gabinete de una coleccionista de insectos, planteando una reflexión sobre las relaciones que se establecen entre el individuo y el espacio natural y social que habita, la construcción de la identidad, la idea de género y, sobre todo, la noción de "memento mori".

Las polillas de Bombyx mori, transformadas en una suerte de exvotos salvíficos y clasificadas en relicarios, tratan de garantizar la continuidad de la propia existencia, conservando la integridad de la muda habitable que es el cuerpo, o, al menos, transcendiendo la vida terrenal mediante la vida de la fama.

La coincidencia entre los términos "bombyx mori" y "memento mori" (en el caso del nombre científico del gusano de seda con una clara referencia a la hoja de morera que lo alimenta, y en el segundo, a la muerte), plantea un paralelismo muy sugerente que remite a la dicotomía que se establece en el binomio "vida-muerte". 


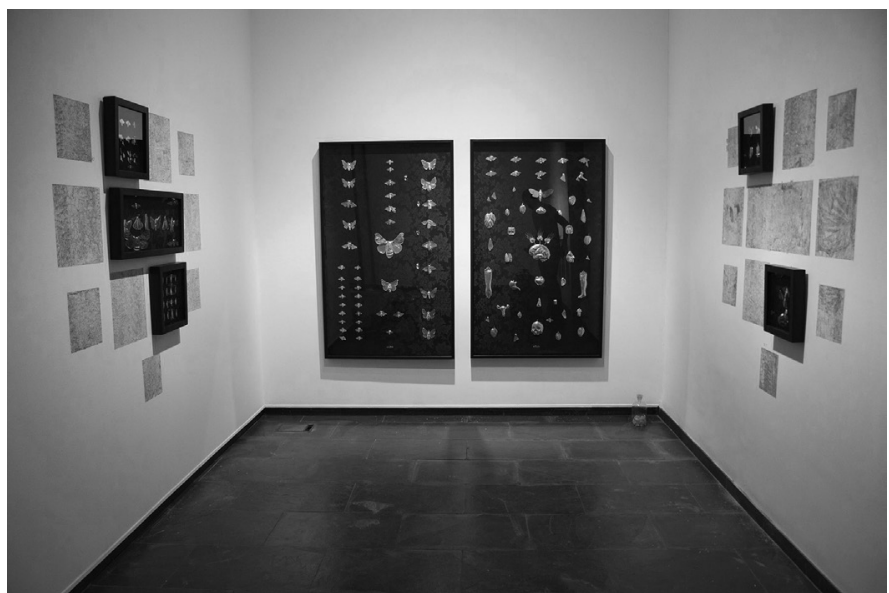

Figura 5. Belén Mazuecos, "La habitación de la entomóloga”, instalación, dimensiones variables. Galería Isabel Hurley, Málaga (España), 2013.

El deterioro del cuerpo nos recuerda el inexorable paso del tiempo y, de esta forma, la metamorfosis del gusano de seda representa el cambio, condensado el ciclo vital en forma de exvotos que reproducen distintos estadios de la vida (nacimiento, crecimiento, apareamiento, reproducción y muerte).

La instalación planteaba la intervención del espacio expositivo con siete piezas-vitrina y varios "strappos" de la capa pictórica del muro".

Un díptico frontal ( 143 x $83 \mathrm{~cm} \mathrm{c/u})$ centraba la instalación: la vitrina de la izquierda presentaba la colección de mariposas rigurosamente clasificadas de una entomóloga (identificada con la cartela bombyx mori), mientras que a la derecha, los exvotos de bombyx mori comenzaban a desmembrarse y a transformarse en pies, órganos, miembros del cuerpo, etc, salpicados por las hojas de morera, evocando la imagen de una vanitas barroca.

A ambos lados se disponían otros pequeños marcos (4 módulos de $33 \mathrm{x} 33 \mathrm{~cm}$ y uno de 67 x $33 \mathrm{~cm}$ ) y se practicaban diversos "strappos" del muro, en distintos puntos de su superficie, arrancando la capa pictórica para sugerir la presencia-ausente de otros marcos removidos con el paso del tiempo. Como si de catas arqueológicas se tratase, la capa de pintura blanca de la pared dejaba visibles capas pictóricas más profundas (aludiendo, así, a los diferentes estratos de la memoria y, nuevamente, al flujo continuo del devenir).

Un frasco de cristal custodiaba un puñado de capullos de seda, a modo de relicario. El parangón entre la habitación de un entomólogo y una capilla de iglesia, resultaba evidente, pues la instalación conformaba una suerte de altar.

Para todas las piezas, se utilizó tela de Damasco negra sobre la que fueron clavados con alfileres todos los exvotos de estaño, repujados artesanalmente a mano uno a uno. 


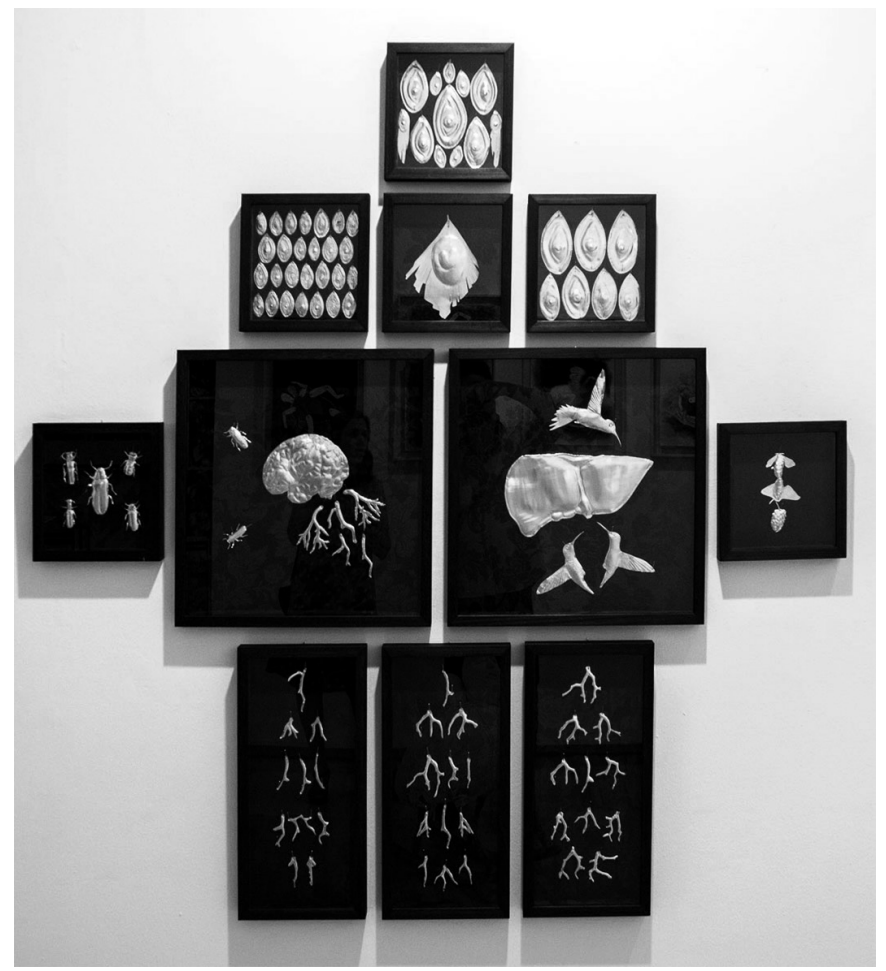

Figura 6. Belén

Mazuecos,

"Altarpiece",

exvotos de estaño repujado y tela de damasco, instalación, dimensiones variables. Museo de Almería (España), 2014.

\section{Proyecto "Altarpiece”}

El proyecto anteriormente descrito abrió una línea de trabajo que dio pie a obras posteriores como "Altarpiece." La instalación "Altarpiece" (pieza de altar) continuó el proyecto "La habitación de la entomóloga", configurando una suerte de retablo geométricamente organizado en cuerpos y calles. Once piezas-relicario a modo de encasamentos, contenían fastuosos exvotos de estaño repujado montados sobre tela de damasco negra que representaban distintos elementos del reino vegetal, mineral y animal (moras, corales, polillas de bombyx mori, termitas, carcomas, ojos, órganos humanos, plumas de pavo real, colibríes, etc.,) como metáfora y reinterpretación del género de la vanitas, pero también de la práctica de coleccionar objetos raros y curiosos que dio lugar a los gabinetes de curiosidades y cámaras de las maravillas. De esta manera, a través del retablo como escenario y como vehículo para la representación narrativa se planteaba no solo una reflexión sobre la vida y la muerte sino también sobre la dicotomía entre presentación y representación, el coleccionismo y la propia práctica artística (Figura 6). 


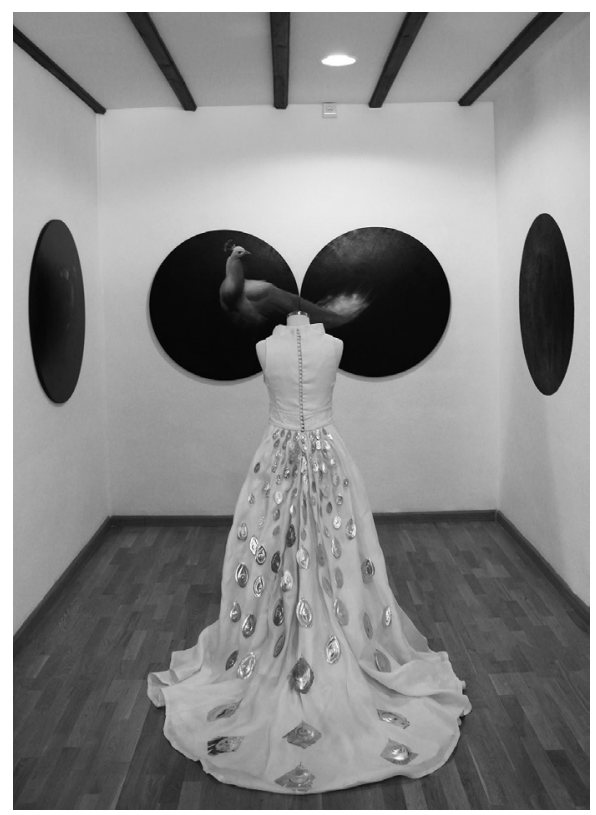

Figura 7. Belén

Mazuecos, "Ojos que no ven", instalación, dimensiones variables, El Arsenal, Córdoba (España), Festival Miradas de Mujeres MAV, 2014.

\section{Proyecto “Ojos que no ven...”}

Otro proyecto integrado en esta línea de trabajo es “Ojos que no ven...” presentado en 2014 en el espacio La Cajita de El Arsenal de Córdoba (España) en el marco del Festival Miradas de Mujeres organizado por la asociación nacional MAV-Mujeres en las Artes Visuales. Esta exposición reflexionaba sobre la vida marital, la gestión armoniosa de la convivencia y la adaptación al cambio (evocada por el renacimiento del ave fénix). Exvotos de ojos jalonaban la cola de mi vestido de novia, estableciéndose un parangón con la fastuosidad de un pavo real albino y su baile de cortejo. Los ocelos (cuya función biológica se asocia al mimetismo), remitían al mito clásico de Argos y los celos de Hera. Pero, por el contrario, el leucismo total del pavo real blanco sugería la pérdida de visión y, metafóricamente, la idea de confianza ciega entre los cónyuges (Mazuecos en MAV, 2014, p. 25) (Figura 7).

\section{Proyecto "Allí donde nace el peligro crece la salvación"}

La instalación "Allí donde nace el peligro, crece la salvación..." continúa indagando en los mismos temas que los proyectos precedentes, ampliando una obra anterior homónima de menor escala realizada en 2010 y configurando una suerte de retablo geométricamente organizado en calles y cuerpos, acompañado de una pieza objetual exenta. Diez vitrinas-reli- 

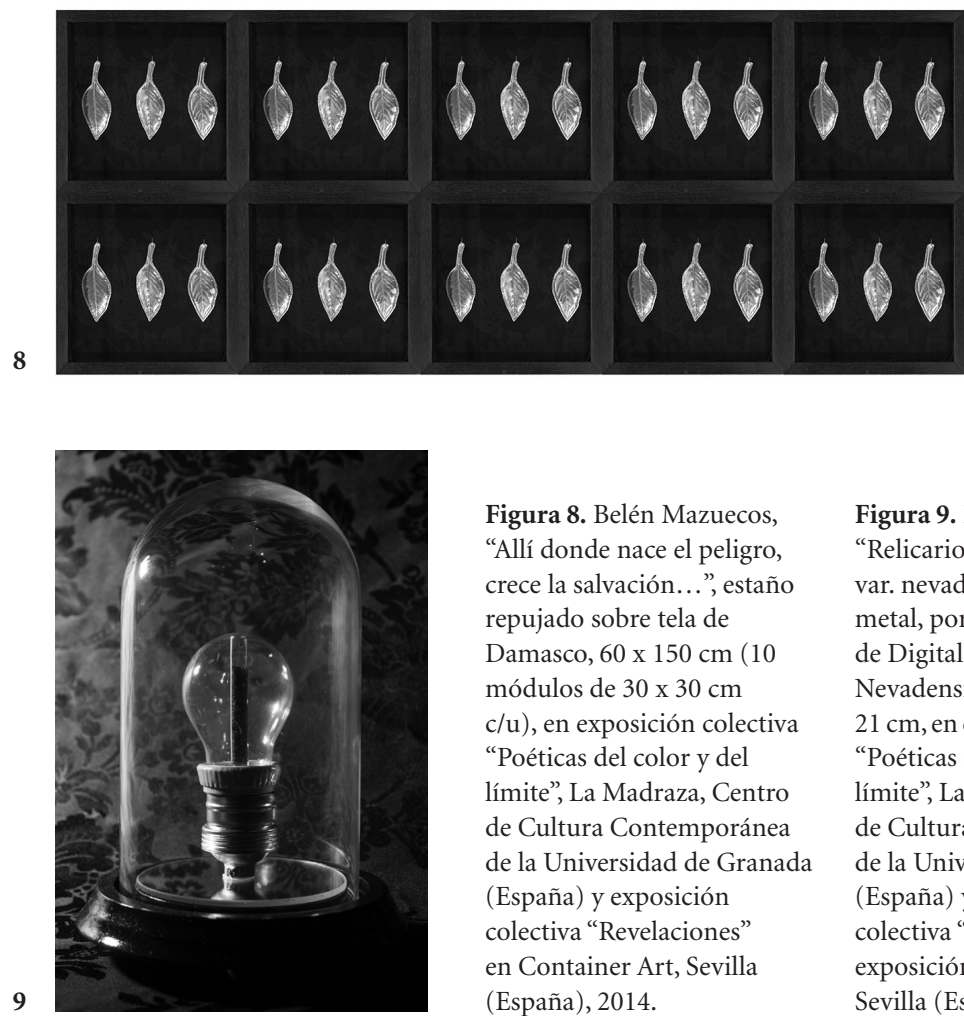

Figura 8. Belén Mazuecos, "Allí donde nace el peligro, crece la salvación...”, estaño repujado sobre tela de Damasco, 60 x $150 \mathrm{~cm}(10$ módulos de $30 \times 30 \mathrm{~cm}$ c/u), en exposición colectiva "Poéticas del color y del límite”, La Madraza, Centro de Cultura Contemporánea de la Universidad de Granada (España) y exposición colectiva "Revelaciones" en Container Art, Sevilla (España), 2014.
Figura 9. Belén Mazuecos, "Relicario (Digitalis purpurea var. nevadensis)", cristal, metal, porcelana y semillas de Digitalis purpurea var. Nevadensis, fanal de 16 x 16 x $21 \mathrm{~cm}$, en exposición colectiva "Poéticas del color y del límite”, La Madraza, Centro de Cultura Contemporánea de la Universidad de Granada (España) y exposición colectiva "Revelaciones" exposición Container Art, Sevilla (España), 2014.

cario a modo de encasamentos contienen fastuosos exvotos de estaño repujado montados sobre tela de damasco negra que representan hojas de la planta endémica de Sierra Nevada (Granada, España), “Digitalis purpurea var. Nevadensis”; mientras que una bombilla contenida en un fanal, custodia en su interior las semillas de la planta en una probeta de cristal que sustituye al filamento incandescente.

La digitoxina, sustancia derivada de la Digitalis purpurea, es un poderoso cardiotónico muy utilizado en medicina, aunque letal en grandes dosis. Entre sus efectos adversos, provoca una alteración de la percepción visual denominada xantopsia (parangonable a las visiones místicas), consistente en ver halos luminosos. "Allí donde nace el peligro, crece la salvación..." plantea, en definitiva, una metáfora del equilibrio inestable que rige la relación del individuo con su entorno natural y de la difusa línea que separa conceptos contradictorios como vida y muerte, salud y enfermedad o amor y odio (Mazuecos en Vallejo Delgado y López Vílchez, 2014, p. 70) (Figura 9).

El título, que parafrasea un paradójico verso del poeta alemán Hölderlin, incide, precisamente, en la dualidad veneno-antídoto, problema-solución, peligro-salvación. 


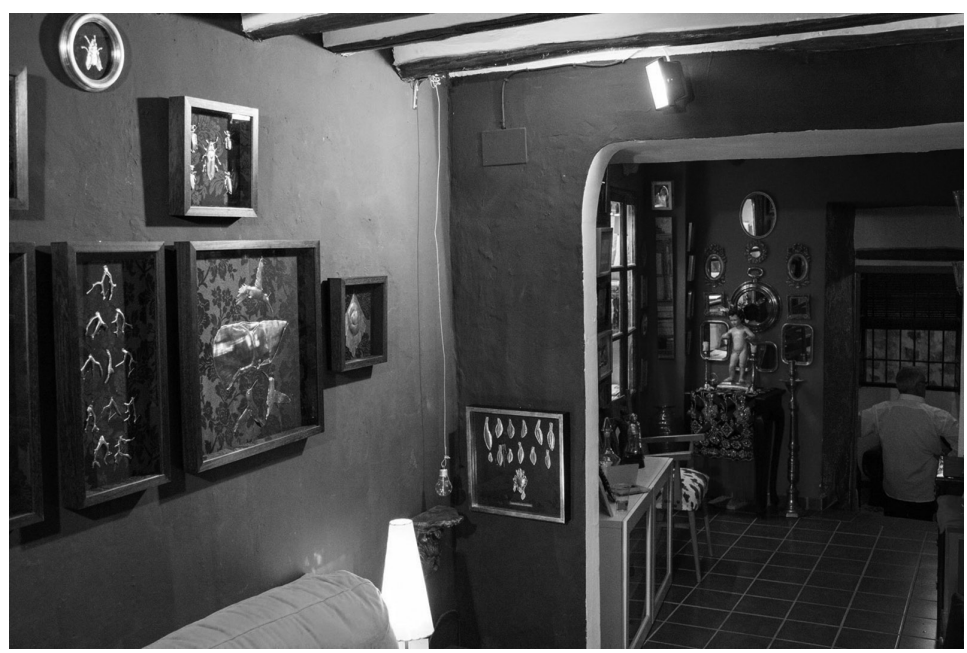

Figura 10. Vista de la exposición “Wunderkammer”, La Sala de Blas, Archidona (Málaga, España), 2014.

\section{Proyecto "Retablo"}

Con los proyectos expositivos "Wunderkammer" en el espacio doméstico de La Sala de Blas en Archidona (Málaga, España) en junio de 2014 y "Retablo" en la galería $41 \mathrm{~m} 2$ (Jaén, España) un año después, se cierra temporalmente este ciclo de trabajos durante unos años, reabriéndose en 2021 en proyectos que combinan dibujo tradicional y exvotos (Figura 10).

"Wunderkammer" y "Retablo" reúnen gran parte de las piezas de exvotos producidas en los años anteriores (añadiendo algunas nuevas producidas, en cada caso, con motivo de estas nuevas muestras), en dos nuevos contextos expositivos de apariencia muy singular. En el primer caso, las obras conviven en un espacio privado con los elementos de mobiliario de la vivienda habitual del artista y gestor cultural "Blas" (pseudónimo usado por Francisco Javier Toro) -que organiza exposiciones temporales en su propia casa-, camuflándose entre distintos objetos raros y curiosos de su propia colección particular, entre los que se cuentan exvotos populares. En el segundo caso, toda la producción se concentra en la pared frontal, componiendo una suerte de retablo de altar. Esta nueva presentación de las obras en un receptáculo expositivo con apariencia de ermita, les confiere otra significación específica. La intervención artística "Retablo" configura una suerte de pala de altar geométricamente organizada en cuerpos y calles que transforma y sacraliza el espacio expositivo imprimiéndole nuevas connotaciones. Varias piezas-relicario a modo de encasamentos, custodian fastuosos exvotos de estaño repujado montados sobre tela de damasco 
negra que representan distintos elementos de carácter salvífico (polillas de bombyx mori, hojas de digitalis purpurea nevadensis, moscas, órganos humanos, etc.,)

\section{Reflexiones finales}

En la escena artística contemporánea española algunos artistas como Andrés Monteagudo, Marina R. Vargas, Pilar Albarracín o Aitor Saraiba han conectado sus obras con la tradición del exvoto, inspirando algunos de sus trabajos en esta costumbre popular y conectándolos con su carácter salvífico con distintas referencias a elementos votivos pero, en ningún caso, produciendo exvotos con la misma técnica tradicional del repujado de metal empleada en la fabricación de los elementos originales.

Mis proyectos, sin embargo, recurren al estaño y a la aplicación de esta técnica particular, para vehicular un discurso centrado en la angustia existencial, que encuentra una vía de expresión perfecta en la producción de estos objetos metálicos, con apariencia de exvotos pero que representan, en muchos casos, elementos inusuales que producen extrañamiento. El dibujo y la pintura se encarnan en esta nueva disciplina, ampliando mis líneas de investigación y producción artística hacia el campo del arte expandido.

Actualmente, trabajo en la búsqueda de nuevas fórmulas para la combinación del dibujo tradicional con las piezas de exvotos metálicos, componiendo polípticos como el titulado "Resiliencia (El laurel de la reina)", de reciente creación.

Durante las primeras tres semanas de confinamiento domiciliario a causa de la pandemia del Covid 19, fui realizando cada día un exvoto representando a escala real una hoja de laurel. Esta rutina adquirió un carácter casi terapéutico, culminando una vez me adapté a la nueva situación de privación de libertad.

Estas piezas, un año después, han constituido el núcleo central del políptico "Resiliencia”, inspirado en el Laurel de la Reina, un árbol centenario localizado en el Convento de San Luis el Real en el municipio de La Zubia (Granada, España), donde diferentes escritos históricos narran que entre sus troncos y hojas se refugió la reina Isabel la Católica para evitar ser apresada por los árabes. El episodio ocurrió cuando la reina se desplazó a este paraje -situado a una altitud considerable- para ver desde la distancia el cerco de Granada, el 25 de agosto de 1491, acompañada por un ejército de dos mil hombres. Boabdil, enterado de la noticia, envió a uno de sus mejores capitanes, Alhamar el Cegri, al frente de ocho mil jinetes. La batalla fue desigual y la reina tuvo que esconderse en un frondoso bosque de laureles cercano. Su supervivencia, protegida por la pantalla salvífica de hojas de laurel, permitió la toma de Granada varios meses después.

Este suceso histórico es conectado con la leyenda de Apolo y Dafne, descrita por Ovidio en su Metamorfosis, donde el laurel vuelve a asumir un papel protector al permitir a la ninfa escapar del dios, metamorfoseándose en dicho árbol, y también evoca una anécdota personal de la infancia, un recuerdo lejano, una inocente travesura en la que yo misma a una edad muy temprana me escondí en casa tras una cortina para observar la reacción de mi madre. 

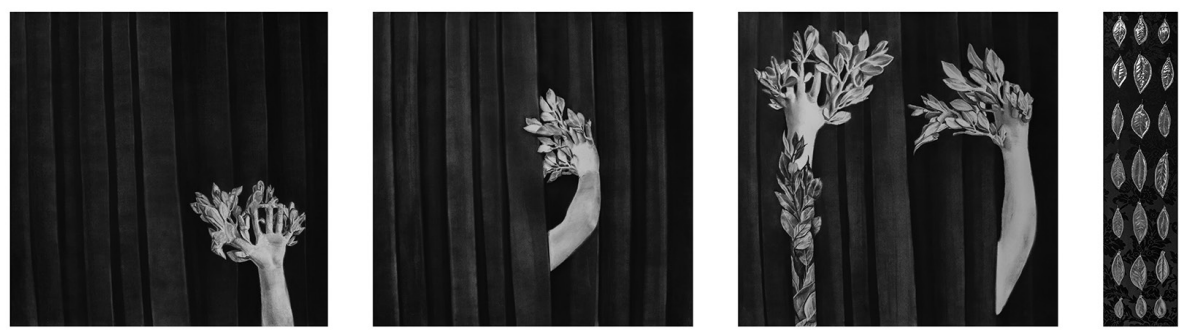

Figura 11. Belén Mazuecos, "Resiliencia (El laurel de la reina)", políptico compuesto por tres piezas de carboncillo sobre papel $(85 \mathrm{x} 85 \mathrm{c} / \mathrm{u})$ y una pieza con exvotos de estaño repujado sobre tela de brocado (85 x $20 \mathrm{~cm}$ ), exposición colectiva “Granada, jardín abierto”, Palacio del Almirante, Granada, España, 2021.

Todas estas capas de significación se solapan componiendo una estratigrafía densa, y adquieren sentido con la experiencia del confinamiento, con la referencia al propio hogar como espacio seguro y a la cortina como interfaz con el mundo hostil exterior, tras la que acecha el peligro del coronavirus.

Esta obra habla de la resiliencia, que se define como la capacidad que tiene una persona para superar circunstancias traumáticas y adaptarse a las adversidades. Los exvotos facilitan en cierta medida esa capacidad y también en mi caso, el repujado de hojas de laurel de estaño y el arte cumplieron su misión salvífica, permitiéndome extraer lo positivo de la situación (Figura 11).

\section{Notas}

1. Más información sobre este proyecto en: http://www.aitorsaraiba.com/dibujos-curati vos [Fecha última consulta: 29/04/2021].

2. Más información sobre este proyecto en: http://feriamarte.com/la-socializacion-delarte/ [Fecha última consulta: 25/04/2021].

3. Cfr. Catálogo "Premio Pepe Espaliú’07", Instituto de la Juventud, Consejería para la Igualdad y el Bienestar Social, Junta de Andalucía.

4. Más información sobre este proyecto en: https://milan.cervantes.es/FichasCultura/ Ficha86235_24_1.htm [Fecha última consulta: 25/04/2021].

5. Revisar contenido de la exposición completa en http://www.isabelhurley.com/exposi ciones.php?lang $=$ esp\&fecha $=$ pasadas\&expo=1028 [Fecha última consulta: 25/04/2021] . 


\title{
Bibliografía y webgrafía:
}

Barbancho, J. R. (2009). "El arte actual en el campo expandido. La hibridación de los géneros”, en http://juanramonbarbancho.blogspot.com.es/2009/10/el-arte-actual-enel-campo-expandido-la.html [Fecha de consulta: 21/09/2016].

Barro, D. (2015). "La pintura, lo pictórico y otra vez la pintura" en Sobrino, M. L. y Fernández, A. (eds.) Arte + Pintura. Consello da Cultura Galega, Santiago de Compostela.

Guash, A. M. (2009). Autobiografías visuales. Del archivo al indice. Madrid: Ediciones Siruela. Jamis, R. (2000). Frida Kahlo. Barcelona: Circe Ediciones.

Kettenmann, A. (1994). Kahlo. Taschen.

Kriss-Rettenbeck, L. (1972). Ex Voto. Zeichen, Bild und Abbild im christlichen Votikbrauchtum. Zürich: Atlantis.

MAV-Mujeres en las Artes Visuales (coord.) (2014). Miradas de Mujeres 2014. Madrid, D.L.: SA 64-2014.

Perniola, M. (2016). El arte expandido (1 a ed.). Madrid: Casimiro Libros.

Reder Gadow, M. (2013). "El exvoto: de la promesa a la materialización” en Campos, Francisco Javier y Fernández de Sevilla (coords.) Patrimonio Inmaterial de la Cultura Cristiana. San Lorenzo del Escorial: Ediciones Escurialenses, pp. 147-158.

Vallejo Delgado, C. y López Vílchez, I. (coords.) (2014). Poéticas del color y del límite. Exposición dedicada a José Guerrero en su centenario. Granada: Centro de Cultura Contemporánea, Editorial Universidad de Granada.

Vázquez, L. (2016). Revisión de la idea de pintura desde una perspectiva contemporánea: Desdibujando los límites, Tesis doctoral, Universidad de Granada.

http://www.isabelhurley.com/exposiciones.php?lang=esp\&fecha=pasadas\&expo $=1028$ [Fecha última consulta: 25/04/2021].

https://milan.cervantes.es/FichasCultura/Ficha86235_24_1.htm [Fecha última consulta: 25/04/2021].

http://www.pilaralbarracin.com/obras.html [Fecha última consulta: 29/04/2021]. https://www.marinavargas.com/ [Fecha última consulta: 30/04/2021].

\begin{abstract}
Cultural transfers between contemporary art and crafts have led to the proliferation of artistic projects that resort to the syncretism of techniques and materials. This article analyses the author's artistic production based on the technique of tin embossing and inspired by the manufacture of votive offerings, a widespread phenomenon in Catholic and Protestant countries, Andalusia being one of the regions of Spain with the highest incidence.

Several works are presented in which this tradition is reinterpreted, generating a new symbolic universe with handmade votive offerings.
\end{abstract}

Keywords: contemporary art - crafts - tin embossing - votive offerings - artistic project hybridisation. 
Resumo: As transferências culturais entre a arte contemporânea e o artesanato têm levado à proliferação de projetos artísticos que recorrem ao sincretismo de técnicas e materiais. Este artigo analisa a produção artística do autor baseada na técnica do estanho em relevo e inspirada na confecção de oferendas votivas, fenômeno bastante difundido em países católicos ou protestantes, sendo a Andaluzia uma das regiões da Espanha onde há maior incidência.

São apresentadas várias obras nas quais esta tradição é reinterpretada, gerando um novo universo simbólico com oferendas votivas feitas à mão.

Palavras chave: arte contemporânea - artesanato - estanho em relevo - oferendas votivas - pintura expandida - hibridização.

[Las traducciones de los abstracts fueron supervisadas por el autor de cada artículo] 